\section{UN NUEVO SENTIDO DEL LUGAR. LAS NARRACIONES DEL SUR Y LA GEOPOLÍTICA EN EL PROCESO DE RENOVACIÓN DE LA FICCIÓN TELEVISIVA ESPAÑOLA DE GÉNERO CRIMINAL}

\author{
Concepción Cascajosa Virino \\ Universidad Carlos III de Madrid \\ ORCID iD: https://orcid.org/0000-0002-6348-5979 \\ ccvirino@hum.uc3m.es
}

\begin{abstract}
Cómo citar este artículo/Citation: Cascajosa Virino, C. (2018). Un nuevo sentido del lugar. Las narraciones del sur y la geopolítica en el proceso de renovación de la ficción televisiva española de género criminal. Arbor, 194 (789): a473. https:// doi.org/10.3989/arbor.2018.789n3015
\end{abstract}

Recibido: 12 enero 2018. Aceptado: 7 febrero 2018.

RESUMEN: El artículo analiza la ficción seriada producida en España tras la reciente crisis económica desde el punto de vista de la introducción de localizaciones diferentes a la ciudad de Madrid y su relación con temáticas tales como el terrorismo, la inmigración y el tráfico de drogas. El estudio se fundamenta en aportaciones teóricas relacionadas con la representación espacial en el audiovisual, así como en el interés creciente en aplicar conceptos procedentes de la geopolítica al análisis de la ficción televisiva. Los estudios de caso son tres series de ficción criminal recientes: El Príncipe (Telecinco: 2014-2016), Mar de plástico (Antena 3: 2015-2016) y Perdóname, Señor (Telecinco: 2017). Estas tres series han sido ejemplo de un proceso de renovación de la ficción española en términos de producción, narrativa, temáticas y estética con el fin de diferenciarse y encontrar un lugar en los mercados internacionales.

PALABRAS CLAVE: Ficción televisiva; televisión en España; localizaciones; representación espacial; geopolítica.

\section{A NEW SENSE OF PLACE. NARRATIVES OF THE SOUTH AND GEOPOLITICS IN THE PROCESS OF RENOVATION IN SPANISH TELEVISION CRIME DRAMA}

Copyright: (C) 2018 CSIC. Este es un artículo de acceso abierto distribuido bajo los términos de la licencia de uso y distribución Creative Commons Reconocimiento 4.0 Internacional (CC BY 4.0).

ABSTRACT: The article approaches serial fiction produced in Spain during the years of the financial crisis from the perspective of locations introduced from outside the city of Madrid and their relationship with issues such as terrorism, immigration and drug trafficking. This study is based on theoretical contributions about spatial representation in media, and also focuses on the growing interest in applying geopolitical concepts to the analysis of television fiction. The study cases are three recent crime dramas: El Príncipe (Telecinco: 2014-2016), Mar de plástico (Antena 3: 2015-2016) and Perdóname, Señor (Telecinco: 2017). These three series are examples of the renovation process undergone by Spanish television fiction in terms of production, narrative, topics and aesthetics, to make them distinctive and find a place in the international marketplace.

KEYWORDS: Television fiction; television in Spain; localizations; spatial representation; geopolitics. 


\section{INTRODUCCIÓN. LA FICCIÓN TELEVISIVA EN ESPAÑA ANTE LA CRISIS}

Este texto es una aproximación al proceso de renovación de la ficción televisiva española tras el estallido de la crisis económica a través del estudio de caso de tres series recientes de temática criminal que reflejan conflictos de base geopolítica: El Príncipe (Telecinco: 2014-2016), Mar de plástico (Antena 3: 2015-2016) y Perdóname, Señor (Telecinco: 2017). La hipótesis de partida es que, como resultado de los problemas vividos por la ficción televisiva con la crisis económica, creadores, productoras y cadenas tuvieron que apostar por nuevos mecanismos para conectar con las audiencias y encontrar un hueco en los mercados internacionales, y en este contexto la utilización de localizaciones externas a la ciudad de Madrid (el tradicional espacio hegemónico) se convirtió en un elemento de diferenciación. El género de ficción televisiva criminal, el conocido internacionalmente como television crime drama, se convirtió en el género ideal para este proceso debido a su extraordinaria popularidad en el mercado global y a su capacidad para ofrecer temáticas relevantes socialmente. Las particularidades de España como nexo transatlántico, nodo del corredor mediterráneo y frontera sur de Europa, fueron por primera vez aprovechadas por su ficción televisiva para aspirar a unirse a una triple tendencia: la emergencia internacional del television crime drama a partir de la popularidad del Nordic Noir (Peacock, 2014; Turnbull, 2014), el uso de las localizaciones como un valor de producción (Agger, 2017; Jensen y Waade, 2013) y la relevancia de la ficción televisiva que representa el mundo contemporáneo con base geopolítica (Moïsi, 2017; Saunders, 2017).

El análisis espacial ha ido alcanzando relevancia en el análisis fílmico (Christie, 2000; Lefebvre, 2006), y paulatinamente también en el análisis de la ficción televisiva, donde la emergencia en el mercado internacional de la televisión del Nordic Noir acreditó esta renovada importancia de los espacios, tanto por su enriquecimiento de los valores de producción como por su importancia semántica en la narrativa (Toft Hansen y Waade, 2017). A este respecto, Roberts (2016) ha propuesto complementar lo que se conoce en el ámbito anglosajón como spatial turn de los estudios mediáticos (Falkheimer y Jansson, 2006), por el locative turn ('giro locativo'), a través del cual se ha producido una transformación de la importancia dada a la economía cultural del espacio por parte de la producción para televisión. El objetivo principal de este texto, por tanto, es mostrar cómo ese giro locativo (como se podría traducir la expresión) del que habla Roberts también se ha producido de manera gradual en la ficción televisiva española gracias los procesos de innovación realizados por entidades (cadenas, productoras, creadores) tras la crisis económica, motivo por el que las series seleccionadas pertenecen al periodo 2014-2017. Pero antes de pasar al análisis de las series, es necesario establecer adecuadamente las consecuencias de la crisis económica que comenzó en 2008 para la ficción televisiva, la importancia de las nuevas localizaciones en relación con la utilización y la presencia hegemónica de la ciudad de Madrid y la manera en la que la utilización de los espacios y las temáticas de base geopolítica han ido ganando importancia en la televisión internacional a través del género de la ficción criminal.

La ficción televisiva en España vivió un extraordinario desarrollo a partir de la llegada de los operadores privados a comienzos de la década de los noventa, fortaleciendo la industria audiovisual y convirtiéndose en la favorita en los gustos de los espectadores. Tras el éxito sucesivo de Farmacia de guardia (Antena 3: 1991-1995) y Médico de familia (Telecinco: 19951999), que establecieron en gran medida las bases estéticas, narrativas y temáticas de esta nueva ficción en lo que fue en gran medida una rotura con su desarrollo histórico (Cascajosa Virino, 2015), las cadenas apostaron de una manera definitiva por la producción propia de ficción desarrollada por productoras independientes. Con Periodistas (Telecinco: 1998-2002), la ficción producida localmente logró asociarse a nociones de calidad gracias sus generosos valores de producción, rodaje en localizaciones y preocupación por tratar temas de candencia social (Smith, 2009, p. 112). La ficción española siguió floreciendo en los años siguientes, hasta el punto de que Palacio, en su análisis del periodo 2005-2011, se atrevió a hablar de una "Edad de Oro", caracterizada por el vigor industrial, presencia en los mercados internacionales, la renovación de géneros, la recuperación de una ficción de base autoral y su tratamiento del pasado (2012, pp. 65-69). Pero durante este periodo de crecimiento industrial también se comenzaron a manifestar signos de un paulatino estancamiento narrativo y estético que acabaron confiriendo a las ficciones un carácter más acomodaticio. A partir del año 2010, la crisis económica empezó a afectar de una manera clara al mercado televisivo, con un hundimiento del número de producciones: según los datos el anuario OBITEL, el número de programas de ficción pasó de 46 en 2010 a 30 en 2013, incluyendo series semanales, miniseries y seriales diarios (Lacalle, 2011, p. 322; Lacalle, 
Castro y Sánchez, 2014, p. 286). No parece casual que García de Castro y Caffarel, en su estudio de la ficción española en el periodo 2010-2015, afirmaran que "la ficción televisiva nacional vivió la regresión creativa mayor de toda su historia reciente" (2016, p. 191).

El impulso de innovación se hizo relevante no solo pensando en lo perdido tras la llegada de la crisis, sino en las amplias posibilidades de un futuro donde los flujos transnacionales y la apertura de mercados propiciada por la llegada de los servicios de vídeo bajo demanda (VOD) suponían nuevas oportunidades. Es aquí donde el aspecto de los espacios en el que se desarrollan las narrativas se ha convertido en un elemento destacado. Merece la pena recordar que la ficción española producida por las cadenas de ámbito estatal ha sido tradicionalmente centralista, primando la presencia de Madrid por encima de cualquier otro espacio de la geografía, incluso hasta el punto de motivar valoraciones que señalan que en el "ámbito de la ficción televisiva española, el centralismo de Madrid no tiene parangón, sobre todo en las series familiares"(Peris Blanes, 2012, p. 414). Un ejemplo de lo que Edensor denominó el proceso de "espacialización de la nación" (2002, p. xviii) había sido la representación de Madrid en la longeva serie de televisión Cuéntame cómo pasó (TVE1: 2001-), en donde se subraya "el carácter medular de la ciudad como capital política y como emplazamiento donde fijar la historia nacional" (Rueda Laffond, 2011, p. 35). Los casos puntuales en donde la ficción española de ámbito estatal se ha desarrollado en otros lugares se han debido a su carácter absolutamente imprescindible para el planteamiento narrativo, como ocurrió en La dársena del poniente (TVE1: 2006-2007), situada en la Costa de Sol y protagonizada por una familia de navieros; Doctor Mateo (Antena 3: 2009-2011), sobre un médico cosmopolita caído en desgracia que busca recuperar la seguridad en el pueblo costero en el que veraneaba; y Gran Reserva (TVE1: 2010-2013), rodada en La Rioja y protagonizada por una familia dedicada al negocio del vino.

Sin embargo, es necesario hacer un apunte en relación a la manera en la que los espacios han sido representados en las series españolas de ámbito estatal: ha existido una hegemonía de Madrid como principal localización, pero en la inmensa mayor parte de los casos buscando representar una ciudad sin rasgos identitarios reconocibles. Esto no ha sido un hecho casual, sino a menudo una imposición por parte de las cadenas con el fin de que la ficción no se pudiera asociar a un lugar $u$ otro y con ello alienar a una parte de la audiencia, lo que llevó a que entre los profesionales circulara el concepto de que en España la ficción televisiva tenía lugar en el denominado Planeta Series (Cascajosa Virino, 2016, pp. 220-225). Y ello, frente al trabajo identitario más intensivo y de una fuerte base espacial que estaba teniendo lugar en la televisión autonómica (Castelló Cogollos, 2004). De esta forma, a través de esta reducción de los rasgos identitarios de Madrid, se ha pretendido camuflar la escasa diversidad de las localizaciones de la ficción española estatal. Aunque una de las motivaciones que subyacen puede ser que la inmensa mayoría de las productoras se encuentran en Madrid, lo cierto es que, como afirma Peris Blanes contraponiendo la experiencia británica, este hecho "no debería ser una excusa si lo que se pretende es integrar a toda la sociedad en un mismo proyecto nacional" (2016, p. 42). Con el paso de los años, se estableció un irresoluble statu quo: las cadenas preferían estas localizaciones desdibujadas en una ambigua "españolidad" ante el miedo de alienar a las audiencias, así que las productoras carecían de estímulo para buscar otras localizaciones. Sin embargo, la necesidad de innovar en un contexto hostil llevó a apostar por la diversidad geográfica y el aprovechamiento estético de espacios caracterizados por su belleza o exotismo. $Y$ frente a las dificultades de la crisis económica, el abaratamiento de efectos digitales y las ayudas proporcionadas por gobiernos locales y autonómicos favorecieron rodajes fuera de Madrid.

Sin embargo, este giro locativo también ha tenido que ver con la exploración de temáticas de base geopolítica, de forma que el tratamiento de España como frontera sur de Europa les ha dado un punto de densidad de sentido a la vez que, como se verá, ha contribuido a ampliar su atractivo en el contexto del mercado internacional. Sin duda, esta tendencia se puede relacionar con la emergencia de un tipo de ficción que cada vez está resultando de mayor interés desde el punto de vista de la geopolítica, en una relación con la que "la realidad internacional no se convierte únicamente en una fuente de inspiración para los guionistas de las series televisivas. La propia serie se transforma en fuente de inspiración para los actores del mundo, en un movimiento dialéctico cada vez más temible" (Moïsi, 2017, p. 13). Por su parte, en un estudio específico sobre la ficción televisiva de base geopolítica, Robert Saunders estableció sus tres características esenciales: "1) engages international themes via imaginary scenarios; 2) builds "worlds" based on situated social, geographical, and political understandings; and 3) interrogates questions of domestic versus foreign identities via narratives" (2017, p. 7). Tanto Moïsi como Saunders basan sus análisis 
en la capacidad de los creadores de televisión de tomar elementos de la actualidad geopolítica para crear narraciones que ofrecen sugerentes interpretaciones de la misma, algo que se puso de manifiesto con la emergencia de las series sobre terrorismo tras los atentados del 11 de septiembre de 2001 y la manera en la que la temática de la seguridad nacional fue impregnando la ficción televisiva criminal norteamericana (Tasker, 2012). Así, el tradicional localismo del género criminal ha ido dando paso a temáticas sustentadas en los flujos del delito internacional (desde la corrupción al tráfico de drogas y de personas), precisamente por su capacidad para representar un marco identificable por las audiencias de todo el mundo. La emergencia del Nordic Noir estableció que eso era posible para países ajenos a la cultura anglosajona gracias a la eficacia con la que se inspiraron en los formatos y culturas de producción internacionales para la creación de un contenido nacional innovador (Bondebjerg y Redvall, 2015, p. 227).

En el caso del género criminal en la ficción española, hasta los últimos años el desarrollo del género había estado lastrado por la problemática relación de la sociedad española con el pasado dictatorial (Colmeiro, 2001), pero poco a poco fue ganando importancia en las parrillas de televisión al amparo del éxito paralelo de los programas de sucesos (Romero Santos, 2015). También ha sido relevante la propia emergencia del género en el cine español reciente, como se comentará más adelante. Para realizar una aproximación a esta cuestión en la ficción televisiva española reciente se ha optado por la herramienta del estudio de caso, ya que permite un conocimiento más comprensivo al posibilitar tener como puntos de referencia tanto condicionantes de producción como de recepción y trazar relaciones causales. Debido a que este estudio es un esfuerzo de aproximación inicial a un proceso de renovación más amplio, se considera más útil en términos analíticos centrarse en tres casos producidos de forma sucesiva, y a través de ellos determinar la adopción, en un periodo corto de tiempo, del énfasis espacial y de las temáticas geopolíticas como fórmula de creación de series en la ficción televisiva en España de temática criminal. Las tres series elegidas se basan en buscar localizaciones alejadas de Madrid. En principio, la elección de Ceuta como escenario para El Príncipe fue tan novedosa como arriesgada, pero su enorme éxito comercial lo impulsó como una moda de la que se derivan las localizaciones andaluzas de Mar de plástico y Perdóname, Señor. En estos espacios, se desarrollan las tramas de base geopolítica: El Príncipe centrándose en la relación entre terrorismo y tráfico de drogas; Mar de plástico indagando sobre la explotación y tráfico de seres humanos; y Perdóname, Señor sobre el tráfico de drogas y personas en los circuitos de la economía sumergida. En el análisis, se tendrá en cuenta en cada caso el contexto de producción, el uso de localizaciones y su relación con temáticas de base geopolítica, así como aspectos relacionados con la recepción local de las series y su proyección internacional.

\section{EL PRÍNCIPE. UNA CIUDAD AL OTRO LADO DEL MAR}

La ficción televisiva española encontró en el sur de España un filón narrativo a partir del éxito de El Príncipe en 2014, principalmente por emitirse en una cadena generalista como Telecinco y obtener un notable éxito de audiencia, con cifras cercanas a los cinco millones de espectadores de media y picos superiores a los seis millones ${ }^{1}$. Fue la serie con la que debutó la productora Plano a Plano, demostrando un interés que luego sería recurrente en explorar como elemento de diferenciación: un nuevo concepto espacial. Quizás el elemento más significativo de El Príncipe era desarrollarse en un lugar real, la barriada del Príncipe Alfonso en la Ciudad Autónoma de Ceuta, conocida por su alta tasa de paro y analfabetismo y uno de los centros del tráfico de drogas y radicalización yihadista. La premisa fue creada por el guionista Aitor Gabilondo una década atrás, cristalizando en un guion al que, en homenaje a Martin Scorsese, puso como título Malas calles, y al que colocó una imagen de The Wire (HBO: 2002-2008) en la portada. Este último elemento obedecía a que, como en la serie norteamericana, en la que la narrativa estaba fuertemente determinada por la ciudad de Baltimore, Gabilondo colocó un barrio de una ciudad sin identificar como espacio principal donde se desarrollaba una historia policiaca protagonizada por un agente encubierto ${ }^{2}$. Finalmente, Gabilondo decidió re-ubicar la historia en El Príncipe tras conocer por un artículo de prensa que era "el barrio más peligroso de España" (Bárbulo, 2003, 28 de abril). Sin duda, un factor que favoreció la luz verde al proyecto por Mediaset para su emisión por Telecinco fue el éxito de una producción de su división cinematográfica (Telecinco Cinema), el thriller No habrá paz para los malvados (2011, Enrique Urbizu), ganadora de seis premios Goya, incluyendo mejor película y mejor actor para José Coronado, que interpretaba a un policía que investiga un grupo yihadista. En El Príncipe el protagonista era el agente del servicio de inteligencia español (CNI) Javier Morey, que se infiltraba en una comisaría del barrio para investigar una red de reclutamiento de terrorismo yihadista. En ese contexto, iba a mantener una compleja relación con el vetera- 
no policía Fran Peyón (José Coronado), mientras vivía una historia de amor con la maestra Fátima Ben Barek (Hiba Abouk), cuyo hermano Faruq (Rubén Cortada) es uno de los mayores narcotraficantes de la zona.

Desde el primer momento, el barrio de El Príncipe se presenta como un escenario privilegiado para el marco de la acción: desde el punto de vista narrativo dota de realismo a una trama central que se ocupa del tráfico de drogas y del terrorismo yihadista, y desde el punto de vista estético ofrece una localización de un gran exotismo y belleza. En relación con lo primero, se puede considerar que El Príncipe se puede ajustar a lo que Saunders denomina una serie "Exotic-Irrealist", especialmente en lo que tiene que ver con "cinematic elements and high production value, especially in affective use of filming locations" $y$ "intense scrutiny of the 'Other', with frequent use of linguistic marking (namely through the use of Arabic, Russian, Chinese, etc.) to establish social distance" (2017, p. 11), con la salvedad de que se realiza en una localidad que no es extranjera pero sí que sitúa en un contexto de lejanía y contraste étnico y religioso. En este sentido, El Príncipe presenta una interesante historia de amor inter-étnica, aunque el tono pesimista de la serie no permite ofrecer un escenario feliz, sino uno de conflicto. Y así ya está anticipado en una de las líneas de diálogo del primer capítulo, que es rememorada en el desenlace de la misma: "En El Príncipe todo acaba en agua salada: en lágrimas... o en el fondo del mar". Tal y como plantea Paul Julian Smith en su análisis de la serie, "as ever the political, economic, romantic, and erotic remain inseparable. But cross-cultural intercourse (...) is shown in the more troubling and ambitious El Príncipe to be deeply, irresolubly problematic" (2016, p. 111). La serie bordea un ámbito polémico en términos de representación, mostrando a una población musulmana que ha sido en gran medida invisibilizada en la ficción a través de algunos clichés (el terrorista y el traficante de drogas), pero también refleja sus espacios de convivencia pacífica y solidaridad, como el centro cívico en el que trabaja Fátima o la cafetería que regenta su padre, Hassan (Tomás Calleja). La importancia en la serie de la temática geopolítica y su exploración espacial es más evidente incluso en la segunda temporada, que comienza con una operación de los servicios secretos españoles en Malta y en la que los servicios secretos franceses se introducen en la narrativa en una relación más de confrontación que de colaboración sincera con sus colegas españoles. En esta segunda temporada, la trama terrorista se relaciona con la corrupción política y empresarial, revelando la existencia de un "estado profundo" en España, hasta concluir en una cadena de atentados terroristas en Granada y Ceuta que reproducen el modus operandi de los grupos yihadistas que actuaron en Francia y en Bélgica en 2015 y 2016 . Así, por primera vez, una serie española se articuló sobre lo que Moïsi considera el hilo conductor de la geopolítica en la ficción televisiva, "el miedo al terrorismo y la pregunta sobre la naturaleza y la identidad del enemigo" (2017, p. 57).

Desde el punto de vista de su uso estético, hay que resaltar que el barrio de El Príncipe es una localización caracterizada por una belleza pintoresca. Ello es debido a que una parte importante del barrio está formado por infra-viviendas construidas por los propios habitantes, que para combatir la alta humedad han pintado con colores fuertes y vivos, como amarillo chiIlón, verde esmeralda, coral, naranja o bermellón. La ciudad que aparece representada, por tanto, es muy distinta a la prototípica basada en el cemento: colorista, exótica y sorprendente. La representación de la ciudad en El Príncipe es omnipresente a través de múltiples tomas aéreas, que van jalonando la narrativa de cada capítulo. Problemas de seguridad y limitaciones presupuestarias llevaron a que la serie se rodara solo de manera muy puntual en Ceuta, esencialmente en forma de tomas áreas, localizaciones relevantes de la ciudad, como el puerto, y algunos planos con actores. El grueso de las filmaciones tuvo lugar en Madrid y los planos que representaban espacios reales de El Príncipe se completaron con la tecnología Virtual Backlot de la compañía Stargate Studios (Terán, 2014, 26 de febrero), que permite insertar a los personajes en localizaciones virtuales basadas en imágenes filmadas. Por tanto, aunque la serie no se rodó allí, las imágenes que mostraban el barrio de El Príncipe sí que eran reales. Por otro lado, la representación del barrio dio origen a críticas desde una perspectiva post-colonial que resaltaban su "orientalismo" (Aidi, 2015, 12 de octubre), pero tras su estreno los medios locales destacaron su éxito comercial y la manera en la que lograba introducir a una ciudad escasamente representada en la ficción en los televisores (y redes sociales) de los españoles (Matés, 2014, 5 de febrero).

La potencialidad de la serie para generar turismo en la zona llevó a que las autoridades locales firmaran un convenio y otorgaran una subvención de 60.000 euros para lograr que una parte más extensa del rodaje de la segunda temporada tuviera lugar en la ciudad. La cobertura periodística de este rodaje destacó el uso de localizaciones como el Parque Marítimo del Mediterráneo, las Murallas Reales y los miradores, y la posibilidad de aprovechar la serie para potenciar el atractivo 
turístico de Ceuta (Oliva, 2014, 25 de julio). La relación entre tema y espacio fue relevante en los mecanismos de promoción internacional de la serie: en el dossier de venta de Mediaset una página estuvo dedicada a noticias reales relacionadas con las tramas de la serie, y otra a presentar específicamente al barrio de El Príncipe como "another character of the story" 3 . No cabe duda de que estos aspectos contribuyeron a que se vendiera a un total de 35 territorios, incluyendo los principales mercados latinoamericanos, los Estados Unidos (donde se emitió por el operador en español UniMás) y países europeos como Italia (donde fue un gran éxito de audiencias), Portugal y Polonia.

\section{MAR DE PLÁSTICO Y PERDÓNAME, SEÑOR. ANDALUCÍA COMO FRONTERA SUR}

El éxito comercial de El Príncipe supuso un catalizador para que el género criminal se convirtiera en la principal tendencia de la ficción dramática en la televisión española, dando como resultado multitud de proyectos que han explorado el género desde diferentes ángulos, desde el drama familiar (Bajo sospecha [Antena 3: 2015-2016]; Sé quién eres [Telecinco: 2017]) hasta lo sobrenatural [Pulsaciones [Antena: 2017], Estoy vivo [TVE: 2017-]). Pero su innovadora utilización de una localización externa a Madrid basada en el sur de España y su planteamiento narrativo de base geopolítica también tuvo continuadores en dos series de televisión situadas en Andalucía, Mar de plástico y Perdóname, Señor. El hecho de que dos series de ficción de la televisión estatal emitidas con tan poca diferencia de tiempo se desarrollen en Andalucía merece ser resaltado. A pesar de la fuerte interrelación entre la identidad española y la andaluza, la presencia de la comunidad en la ficción estatal ha llegado casi siempre a través de emigrantes fuertemente estereotipados viviendo en Madrid (Ruiz Muñoz, 2009, 1 de septiembre). Entre las excepciones a las ficciones estatales situadas y rodadas en Andalucía se pueden mencionar la ya citada La dársena del poniente, con exteriores en la Costa del Sol, y el serial diario Bandolera (Antena 3: 2011-2013), así como la co-producción internacional Falcón (Sky Atlantic / Canal+ ( ZDF, 2012), adaptación de las novelas de Robert Wilson sobre un agente de policía sevillano. A pesar de que Falcón pasó desapercibida en su emisión en Canal +, la serie demostró las posibilidades de desarrollar un relato criminal en una localización andaluza en un contexto en el que se había producido un impulso a las políticas públicas de fomento de rodajes, favoreciendo que ficciones televisivas internacionales como Game of Thrones (HBO: 2011-) y Penny Dreadful
(Showtime: 2014-2016) se filmaran en Andalucía (Oubernell, 2017, 31 de mayo). Otro factor favorable fue el éxito de dos producciones rodadas en Andalucía y financiadas por los grupos mediáticos que emitirían las series posteriormente. Por un lado, Atresmedia, tanto con la ganadora del Goya a la mejor película, $L a$ isla mínima (Alberto Rodríguez, 2014), como con Mar de plástico, ofreció thrillers sobre sórdidos asesinatos. Por otro, Mediaset, con la taquillera El Niño (Daniel Monzón, 2014), producida por Telecinco Cinema, y Perdóname, Señor, emitida por Telecinco, trataban del tráfico de drogas en la costa de Cádiz. En este segundo caso, en ambas el actor Jesús Castro interpretaba un papel similar.

El título de Mar de plástico, creada por los guionistas Juan Carlos Cueto, Rocío Martínez Llano, Alberto Manzano y Pablo Tébar en el seno de la productora Boomerang TV, hacía referencia a la comarca del Poniente Almeriense, conocida por ese nombre por el elevado uso de invernaderos. El hecho de que buena parte de los trabajadores manuales de la zona sean inmigrantes ha sido motivo de recurrentes conflictos en la zona, el más notorio en la localidad de El Ejido en 2000. La serie tenía un planteamiento característico de la ficción criminal europea, con un asesinato que sirve de detonante de la acción y que pone de manifiesto los secretos y miserias de ese lugar. En este caso, se trata de la ficticia localidad de Campoamargo en Almería, donde el asesinato de la hija de la alcaldesa motiva la llegada del sargento Héctor Aguirre Millán (Rodolfo Sancho) para investigar el caso. Campoamargo tiene una elevada población gitana, así como de inmigrantes procedentes de América Latina, África y Europa del Este, lo que otorga a la serie una riqueza étnica inédita en la ficción española. A eso se añaden aspectos poco explorados que se acaban convirtiendo en elementos relevantes de la trama, como el hecho de que Héctor sea un veterano de la guerra de Afganistán. Mar de plástico se ajusta a lo que Saunders, en su categorización de las series geopolíticas, ha denominado como procedural-localised, una modalidad especialmente habitual en el Nordic Noir donde el asesinato inicial sirve para mostrar las debilidades del estado del bienestar, se explora la otredad (especialmente a través de los personajes extranjeros) y se reflejan en la narrativa los flujos ilegales de la globalización (2017, p. 17). En Mar de plástico ello es especialmente patente a través de la exploración de la inmigración ilegal y de la trata de mujeres, que acaba siendo la motivación del asesinato inicial. Por otro lado, como en El Príncipe, también aquí hay una trama con una historia de 
amor inter-étnica, aunque menos central en la narrativa, entre Lucas (Jesús Castro), un racista joven local, y la inmigrante Fara (Yaima Ramos).

A pesar de todo y de que el escenario era explícitamente identificado en el título con la realidad de esa comarca almeriense, en la serie se optó por un nombre ficcional para la localidad donde se desarrolla la historia (una combinación de los lugares de rodaje Níjar, Campohermoso, San Isidro, Vícar, Balerma, Almerimar y El Ejido), así como por comenzar cada capítulo con un rótulo que recordaba el carácter de ficción de la trama. En todo momento la serie se presentaba como una narrativa de frontera: de hecho, el primer capítulo se iniciaba con un plano cenital (claramente inspirado en el reciente éxito de La isla mínima) que comenzaba en el mar y recorría toda la costa hasta mostrar los invernaderos. Hay que resaltar la importancia del paisaje en narrativas televisivas recientes como la serie norteamericana Breaking Bad (AMC: 2008-2013), una de las referencias explícitas para Mar de plástico, en palabras del director Javier Quintas, en su propósito de "hacer del paisaje un personaje más" a través de recursos como los planos abiertos y no rehuir la aparición del sol (Redondo, 2015, 23 de julio). El cromatismo adoptaba una fuerte tonalidad amarilla, que evidenciaba la hostilidad de los paisajes donde se desarrollaba la serie. Esta representación del paisaje en relación con una nueva España que, como resultado de la inmigración, es más diversa que nunca, se puede interpretar como una prolongación televisiva de una tendencia que Marvin D'Lugo detectó en el cine español a partir de la década de los 90, de forma que ha venido a "reflect changes in the political, social and cultural communities that are its diverse national audience", siendo ejemplo de una idea de la modernidad que ha superado el proyecto europeo para marcar "the more recent recognition of the globalizing project" (2010, p. 128).

La apuesta de Mar de plástico fue considerada exitosa, con tres millones setecientos mil espectadores de media para su primera temporada, lo que llevó a que fuera renovada para una segunda que obtuvo resultados peores pero aceptables. Sin embargo, la acogida de la serie fue negativa por parte de las autoridades de la zona, hasta el punto de que el alcalde de la localidad de El Ejido acusó a la serie de "intentar estigmatizar" a la provincia, polémica que fue respondida por el productor Jorge Redondo, que recordó en unas declaraciones que las autoridades locales habían leído dos de los guiones de la serie y que se había invertido en la zona medio millón de euros solo en la primera parte de su rodaje (Morales, 2015, 24 de septiembre). Como en otros casos, el paso del tiempo y el éxito comercial de la serie hicieron variar esta posición de partida, y en noviembre de 2016 la serie recibió un premio de la diputación de Almería (como El Ejido, gobernada por el Partido Popular) en el marco del Festival de Cine de Almería (Cabrera, 2016, 7 de noviembre). Localización y planteamiento argumental hicieron destacar a Mar de plástico: en el MIPCOM de 2015 fue elegida como uno de los nuevos proyectos de ficción más destacados por la consultora The Wit y al año siguientes sus derechos para Europa y Latinoamérica fueron adquiridos por Netflix (Fernández, 2016, 22 de octubre).

Perdóname, Señor, creada por Frank Cuesta y escrita por Antonio Onetti, narraba la historia del regreso a su localidad natal de Barbate (Cádiz) de la monja Lucía Medina (Paz Vega), y el reencuentro con el hijo que su hermano ha criado como propio, Rafa (Jesús Castro), y con su antiguo amor y padre de Rafa, Bruno Lachambre (Stany Coppet). La trayectoria de ambos hombres es de colisión, ya que el primero acaba de introducirse en el contrabando de hachís y el segundo es uno de los narcotraficantes más poderosos de la zona. El creador Frank Ariza nació y creció en la localidad de Barbate, y en las entrevistas que concedió a propósito del rodaje y estreno de la serie estableció la narrativa desde una premisa más local y autobiográfica, resaltando, con relación a la elección de la localización, que Madrid "no deja de ser una ciudad y es mucho más impersonal. Creo que los valores de la familia que todos hemos vivido, los representa mucho más cercano un pueblo" (Redacción Vertele, 2017, 24 de mayo). Uno de los aspectos más destacados de Perdóname Señor es su poco complaciente retrato de la situación de la zona, especialmente teniendo en cuenta que Barbate es citada de manera expresa como el lugar donde se ambienta la serie, frente a la ficcional Campoamargo de Mar de plástico. Así, se muestra la dependencia de la economía local de lo que viene del mar, de manera legal e ilegal. La conservera local se encuentra amenazada por el cierre, lo que desencadena una huelga liderada, entre otras, por la cuñada de Lucía y madre adoptiva de Jesús, Antonia (Estefanía de los Santos). Las autoridades públicas no tienen soluciones para este problema, como tampoco para ninguno de los otros de la zona, lo que lleva a Bruno a convertirse en benefactor en la sombra para salvar la empresa. El fracaso del estado en la zona es uno de los temas de la serie. De hecho, las autoridades públicas parecen estar ausentes del relato, salvo para ejercer represión, como es el caso del teniente Menéndez 
(José Manuel Seda), el guardia civil que lidera la investigación que, siguiendo la categorización de Saunders, permite adscribir la serie al procedural-localised. Así, la historia cuenta con dos detonantes argumentales, el regreso de Lucía y el encarcelamiento y asesinato en prisión de El Rojo (Antonio de la Torre), lo que obliga a Rafa a pasar a liderar su negocio de narcotráfico. El eje geopolítico central de Perdóname, Señor tiene que ver con la dinámica entre la dimensión local de este tráfico de drogas, encarnada por la generación sin horizontes a la que pertenece Rafa, y la dimensión internacional que encarna Bruno, que aspira a ser un empresario reconocido por su compromiso con la zona mientras articula una red de tráfico de drogas con un cartel mexicano y mantiene un difícil equilibro con su socio en Marruecos, país a donde se extiende su conflicto con Rafa. Por otro lado, Lucía lucha junto con el padre José (Antonio Zabálburu) para sacar a una mujer, Sibebi (Chanel Terrero), de una red de explotación sexual. De esta manera el tráfico de drogas y de personas se muestran como las dos caras del mismo tipo de criminalidad internacional.

El elemento más distintivo de Perdóname, Señor es la utilización, casi omnipresente, en la narrativa del paisaje marítimo, algo ligado a la trama del narcotráfico, y la presencia de múltiples escenas de acción a lo largo de la serie, que incluyen la recogida de droga en la playa y diferentes persecuciones marítimas, desarrolladas en localizaciones de la playa de la Hierbabuena, la playa de Nuestra Señora del Carmen, la playa de Los Alemanes y las Marismas del Barbate. Pero el mar también está ligado al ocio y al placer: la suntuosa casa de Bruno, uno de los espacios centrales de la narrativa, presenta una enorme terraza al mar donde tienen lugar muchas escenas de su vida doméstica. La playa se relaciona sobre todo con las subtramas amorosas de Rafa con la hija del teniente Menéndez, Paula (Lucía Guerrero), y de Lucía y Bruno, que viven su reencuentro en una escena donde es claramente visible uno de los referentes arquitectónicos de la zona, el faro de Cabo Trafalgar. Sin embargo, el trágico clímax de la serie, donde, incapaz de resolver el conflicto entre padre e hijo, Lucía muere de un disparo, se sitúa en las Marismas de Barbate, un paisaje lleno de contraste y acantilados donde las pasiones humanas extremas encuentran una adecuada expresión metafórica. Frente a la estilización de Mar de plástico, Perdóname, Señor realiza una aproximación más naturalista de sus localizaciones, lo que se pone de manifiesto especialmente en los espacios urbanos, como el uso que se da a la lonja de la localidad como escenario de la trama relacionada con la fábrica de conservas que sirve para explorar la menguante dependencia de la localidad del pescado. La serie también se rodó en otras localizaciones del litoral, así como, aprovechando la cercanía geográfica, en Tánger, donde se muestran localizaciones tan distintivas como su zoco. Perdóname, Señor, al contrario que otros casos analizados, se rodó con la colaboración del ayuntamiento de la localidad de Barbate, que firmó un convenio con la productora para favorecer un rodaje que, en estimaciones hechas públicas, iba a proporcionar a la localidad unos ingresos de en torno el millón de euros. En declaraciones públicas, por las autoridades se indicó el triple beneficio de posicionarse como lugar de rodaje, promocionarlo como destino turístico y, también, mostrar "un gran pueblo con ganas de salir para delante" (V. B., 2016, 1 de abril), lo que se puede situar más en términos de una reivindicación del orgullo local. Quizás esto último tenía que ver con la presencia de actores conocidos como Paz Vega y con la confianza en el éxito de la serie, que logró dos millones ochocientos mil espectadores de media. Además, como en el resto de los ejemplos citados, el atractivo internacional de la serie puso de manifiesto con la venta a la plataforma de televisión de pago latinoamericana DirectTV (Redacción Audiovisual451, 2017, 18 de julio).

\section{CONCLUSIONES}

En las páginas precedentes, se han analizados tres estudios de caso que permiten trazar algunos de los mecanismos utilizados por la ficción televisiva española en el periodo posterior a la crisis económica. Concretamente, estas series sirven de exponente de una innovación articulada sobre estrategias de producción, tratamiento espacial y exploración de temas más relevantes y de base geopolítica. Situar sus tramas argumentales en la ciudad autónoma de Ceuta (El Príncipe) y Andalucía (Mar de plástico y Perdóname, Señor) permitieron a sus respectivas productoras aprovechar ayudas públicas y encontrar localizaciones nunca vistas en la ficción televisiva, muchas de ellas (hasta, podemos decir, la playa almeriense de la ficcional Campoamargo que visitan ocasionalmente los personajes) con indudable potencial turístico. Por ello, a pesar de que en su mayor parte fueran recibidas en su estreno con cierta hostilidad política, su éxito comercial aseguró un claro cambio de opinión al respecto. Y es que, como se ha puesto de manifiesto en el análisis, se aprovechó el indudable atractivo de estas localizaciones, pero también se han situado en ellas historias con temas controvertidos sobre el terrorismo y el tráfico de drogas y de personas, 
temáticas exploradas desde una óptica geopolítica reconocible tanto para las audiencias locales como globales. Sin duda, se puede hacer una lectura crítica en relación a que en la ficción española sea necesario explorar estas temáticas para introducir tramas donde haya personajes extranjeros y pertenecientes a minorías étnicas, pero para esa cuestión sería necesario un análisis específico sobre la diversidad en la serialidad española, algo que queda fuera de los objetivos de este texto. En todo caso, hay que señalar que, en un contexto de una ficción televisiva caracterizada por su centralismo y reticencia a tratar temas controvertidos, estas tres series han contribuido decisivamente a ampliar y diversificar los horizontes de la ficción televisiva española. También es necesario señalar que las características presentes en estas tres series no parecen haberse quedado en lo excepcional, ya que entre 2016 y 2018 se pueden contabilizar numerosos proyectos que han seguido su senda. Así, entre las series de este periodo que combinan ambición temática con localizaciones fuera de Madrid se pueden citar las siguientes: La Zona (Movistar: 2017) en Asturias, La Peste (Movistar: 2018-) en Sevilla, Félix (Movistar: 2018-) en Andorra, La verdad (Telecinco: 2018-) en Cantabria, Fariña (Antena 3: 2018) y Vivir sin permiso (Telecinco: 2018-) en Galicia y Presunto culpable (Antena 3: 2018) en País Vasco... Aunque para valorar el calado y vigencia de estos cambios en la ficción televisiva española, será necesario un estudio específico que tenga en cuenta una muestra más amplia tanto numérica como temporalmente. El hecho de que las tres series analizadas ( $E I$ Príncipe, Mar de plástico y Perdóname, Señor) hayan tenido saludables ventas internacionales en un momento en el que ello se ha convertido en un objetivo esencial para la ficción española muestra la viabilidad comercial de este nuevo sentido del lugar de la ficción televisiva de género criminal.

\section{NOTAS}

1. Datos de audiencia de las series analizadas en el texto obtenidos en todos los casos del portal Fórmula TV (http://www.formulatv.com [Fecha de consulta: 3-12-2017])
2. Entrevista personal con Aitor Gabilondo, 16 de abril de 2016.

3. Dossier de ventas internacional de El Príncipe disponible en: http://sales.

\section{BIBLIOGRAFÍA}

Agger, G. (2017). Geopolitical Location and Plot in The Night Manager. Journal of Scandinavian Cinema, 7 (1), pp. 27-42. https://doi.org/10.1386/ jsca.7.1.27_1

Aidi, Y. (2015, 12 de octubre). La serie El Príncipe: Los juegos de la convivencia. El Diario. [En línea]. Disponible en: http://www.eldiario.es/zonacritica/serie-Principe-juegos-convivencia_6_439266081.html

Bárbulo, T. (2003, 28 de abril). El barrio más peligroso de España. La barriada de El Príncipe, en Ceuta, se vuelca en la inmigración irregular. El País. [En línea]. Disponible en: https:// elpais.com/diario/2003/04/28/ultima/1051480801_850215.html

Bondebjerg, I. y Redvall, E. N. (2015). Breaking Borders: The International Success of Danish Television Drama. En: Bondebjerg, I., Redvall, E. N. y Higson, A. (eds.). European Cinema and Television: Cultural Policy and Everyday Life. Londres: Palgrave Macmillan, pp. 214-238. https://doi. org/10.1057/9781137356888_11

Cabrera, M. (2016, 7 de noviembre). Almería se reconcilia con la serie Mar de plástico. El Mundo. [En línea]. Disponible en: http://www.elmundo.es/ andalucia/2016/11/07/5820c81b461 63f7a458b458e.html

Cascajosa Virino, C. (2015). Formas y contenidos: las estructuras narrativas de la ficción televisiva en España. En: Puebla Martínez, B., Navarro Sierra, N. y Carrillo Pascual, E. (coords.). Ficcionando en el siglo XXI: la ficción televisiva en España. Madrid: Editorial Icono 14, pp. 15-32.

Cascajosa Virino, C. (2016). La cultura de las series. Barcelona: Laertes.

Castelló Cogollos, E. (2004). Mecanismos de construcción de la identidad cultural en las series de ficción: el caso de mediaset.es/ficha.php?id=139 (Fecha de consulta: 10-12-2017).

la televisión autonómica en España. Estudios sobre las Culturas Contemporáneas, 20, pp. 45-77.

Christie, I. (2000). Landscape and "Location": Reading Filmic Space Historically. Rethinking History: The Journal of Theory and Practice, 4 (2), pp. 165-174. https://doi. org/10.1080/13642520050074803

Colmeiro, J. F. (2001). The Hispanic (Dis)Connection: Some Leads and a Few Missing Links. Journal of Popular Culture, 34 (3), pp. 51-68. https://doi.org/10.1111/j.00223840.2001.3404_49.x

D'Lugo, M. (2010). Landscape in Spanish Cinema. En: Harper, G. y Rayner, J. (eds.). Cinema and Landscape. Bristol: Intellect, pp. 117-129.

Edensor, T. (2002). National Identity, Popular Culture and Everyday Life. Oxford: Berg. 
Falkheimer, J. y Jansson, A. (eds.) (2006). Geographies of Communication: The Spatial Turn in Media Studies. Gotemburgo: Nordicom.

Fernández, E. (2016, 22 de octubre). Mar de plástico salta a Netflix. El Mundo. [En línea]. Disponible en: http://www. elmundo.es/television/2016/10/22/5 80a6d44268e3ef5398b460c.html

García de Castro, M. y Caffarel Serra, C. (2016). Efectos de la crisis económica en la producción de contenidos de ficción televisiva en España entre 2010 y 2015. Zer. Revista de Estudios de Comunicación, 21 (40), pp. 177-193. https://doi.org/10.1387/zer.16422

Jensen, P. M. y Waade, A. M. (2013). Nordic Noir Challenging the Language of Advantage': Setting, Light and Language as Production Values in Danish Television Series. The Journal of Popular Television, 1 (2), pp. 259-265. https:// doi.org/10.1386/jptv.1.2.259_1

Lacalle, C. (2011). España: la apuesta por el gran formato. En: Vassallo de Lopes, M. I. y Orozco Gómez, G. (eds.). Calidad de la ficción televisiva participación transmediática de las audiencias: Obitel 2011. São Paulo: Globo, pp. 307-353.

Lacalle, C., Castro, D. y Sánchez, M. (2014). España: el auge de la ficción ambientada en el pasado. En: Vassallo de Lopes, M. I. y Orozco Gómez, G. (eds.). Estrategias de producción transmedia en la ficción televisiva: anuario Obitel 2014. Porto Alegre: Sulina, pp. 273-314.

Lefebvre, M. (ed.) (2006). Landscape and Film. Nueva York: Routledge.

Matés, P. (2014, 5 de febrero). El Príncipe fue lo más visto de este martes en la televisión en todo el país. Ceuta al Día. [En línea]. Disponible en: http://www.ceutaldia.com/articulo/en-comunidad/principe-fuemas-visto-martes-television-todopais/20140205141439137137.html

Moïsi, M. (2017). Geopolítica de las series, o el triunfo global del miedo. Madrid: Errata Naturae.

Morales, V. (2015, 24 de septiembre). Jorge Redondo, productor de Mar de plástico, responde a las críticas: "Es una ficción". Fórmula TV. [En línea]. Disponible en: http://www.formulatv. com/noticias/49574/jorge-redondoproductor-mar-de-platico-respondecriticas-es-una-ficcion/
Oliva, J. (2014, 25 de julio). El rodaje de la segunda temporada de El Príncipe arranca la próxima semana. El Faro de Ceuta. [En línea]. Disponible en: https://elfarodeceuta.es/el-rodajede-la-segunda-temporada-de-elprincipe-arranca-la-proxima-semana/

Oubernell, C. (2017, 31 de mayo). Andalucía, insustituible plató de cine. El Mundo. [En línea]. Disponible en: http://www.elmundo.es/andalucia/ 2017/05/31/592be07ee2704e4253 8b4616.html

Palacio, M. (2012). La ficción televisiva española (2005-2011). Dos o tres cosas que sé de ella. Breviario de imágenes de la Transición. En: Francés, M. y Llorca Abad, G. (eds.). La ficción audiovisual en España: Relatos, tendencias y sinergias productivas. Barcelona: Gedisa, pp. 63-73.

Peacock, S. (2014). Swedish Crime Fiction: Novel, Film, Television. Manchester: Manchester University Press. https://doi.org/10.7228/manchester/9780719086953.001.0001

Peris Blanes, Á. (2012). Nación española y ficción televisiva. Imaginarios, memoria y cotidianidad. En: Saz Campos, I. y Archilés i Cardona, F. (coords.). La nación de los españoles. Discursos y prácticas del nacionalismo español en la época contemporánea. Valencia: Universitat de València, pp. 393-418.

Peris Blanes, Á. (2016). Imaginar la nación a través de la ficción televisiva: memoria, proximidad y vida diaria. Debats, 130 (1), pp. 31-47. https://doi.org/10.28939/iam.debats.130-1.4

Redacción Audiovisual451 (2017, 18 de julio). Perdóname, Señor llega a Latinoamérica y Eslovaquia. Audiovisual 451. [En línea]. Disponible en: https://www.audiovisual451.com/ perdoname-senor-llega-a-latinoamerica-y-eslovaquia/

Redacción Vertele (2017, 24 de mayo). El productor de Perdóname, Señor en Telecinco: "La serie puede herir sensibilidades". Vertele. [En línea]. Disponible en: http://vertele.eldiario.es/noticias/Frank-Ariza_0_1905409481.html

Redondo, D. (2015, 23 de julio). Almería, el nuevo Albuquerque de Breaking Bad. Cadena SER. [En línea]. Disponible en: http://cade- naser.com/ser/2015/07/23/television/1437618783_484176.html

Roberts, L. (2016). Landscapes in the Frame: Exploring the Hinterlands of the British Procedural Drama. New Review of Film and Television Studies, 14 (3), pp. 364-385. https://doi.org/1 0.1080/17400309.2016.1189712

Romero Santos, R. (2015). Mucha policía, mucha diversión. La ficción criminal en la ficción española. En: Puebla Martínez, B., Navarro Sierra, N. y Carrillo Pascual, E. (coords.). Ficcionando en el siglo XXI: Ia ficción televisiva en España. Madrid: Editorial Icono 14, pp. 261-276.

Rueda Laffond, J. C. (2011). Esta tierra es mía: Espacios históricos y geografía de la memoria en la ficción televisiva española. Historia Actual Online, 26, pp. 27-39.

Ruiz Muñoz, M. J. (2009, 1 de septiembre). La representación de los andaluces en televisión. Viejos estereotipos para nuevos formatos. Fundación Audiovisual de Andalucía. [En línea]. Disponible en: https://www.fundacionava.org/?section=recordtables\& action=ficha\&contentid $=1869$

Saunders, R. (2017). Small Screen IR: A Tentative Typology of Geopolitical Television. Geopolitics, pre-print, pp. 1-37. https://doi.org/10.1080/14650 045.2017.1389719

Smith, P. J. (2009). Spanish Screen Fiction. Between Cinema and Television. Liverpool: Liverpool University Press. https://doi.org/10.5949/ UPO9781846315732

Smith, P. J. (2016). Dramatized Societies: Quality Television in Spain and Mexico. Liverpool: Liverpool University Press.

Tasker, Y. (2012). Television Crime Drama and Homeland Security: From Law \& Order to "Terror TV". Cinema Journal, 51 (4), pp. 44-65. https://doi. org/10.1353/cj.2012.0085

Terán, B. (2014, 26 de febrero). El Príncipe, un gran éxito hecho en chro$m a$ : así nos engañan los maestros de los efectos visuales. La Información. [En línea]. Disponible en: http://blogs.lainformacion.com/ telediaria/2014/02/26/el-principeun-gran-exito-hecho-en-chroma-asinos-enganan-los-maestros-de-losefectos-visuales/ 
Toft Hansen, K. y Waade, A. M. (2017). Locating Nordic Noir. From Beck to The Bridge. Londres: Palgrave Macmillan. https://doi.org/10.1007/9783-319-59815-4
Turnbull, S. (2014). The TV Crime Drama. Edimburgo: Edinburgh University Press.

V. B. (2016, 1 de abril). Perdóname rueda el alijo en la playa de un cargamento de hachís. Andalucía Información. [En línea]. Disponible en: http://andaluciainformacion.es/andalucia/583910/ perdoname-rueda-el-alijo-en-la-playa-de-un-cargamento-de-hachis/ 